\title{
The Multiple Faces of Heparin: Opportunities in COVID-19 Infection and Beyond
}

\author{
Ludovic Drouet $^{1,2}$ Job Harenberg ${ }^{3,4}$ Giangiacomo Torri ${ }^{5}$ \\ ${ }^{1}$ CREATIF (Centre de Référence et d'Éducation aux \\ AntiThrombotiques d'île de France), Cardiology Department, \\ Hôpital Lariboisiere, Paris, France \\ 2 Department of Vascular Medicine, Paris Saint Joseph Hospital, Paris, \\ France \\ ${ }^{3}$ DOASENSE GmbH, Heidelberg, Germany \\ ${ }^{4}$ Medical Faculty Mannheim, Ruprecht-Karls-University, Heidelberg, \\ Germany \\ ${ }^{5}$ Istituto di Ricerche Chimiche e Biochimiche G. Ronzoni, Milan, Italy
}

Thromb Haemost 2020;120:1347-1350.

\section{Anticoagulant and Nonanticoagulant Actions of Heparin}

The fascinating multifactorial faces of the polysulfated glycosaminoglycan heparin were reported first by Doyon in 1912. He revealed heparin's nonanticoagulant action when he investigated the effect of peptone on blood coagulation in canine livers. McLean and his mentor Howel observed an anticoagulant effect in the liver when they purified a thromboplastic component from various organs and named it heparin, according the Greek name of its origin ( $\eta \pi \alpha \rho=$ hepar). These contradictory actions of heparin are still observed until today such as they can have disastrous thrombotic side effects in the form of heparininduced thrombocytopenia. ${ }^{1}$

The chemical composition of heparin was discovered by Chargaff and Olson in 1937. They found that the negatively charged heparin binding to positively charged protamine sulfate antagonized the anticoagulant property of heparin. Jorpes and Bergström identified a polysulfated glucosamine/ glucopyranose and uronic acid of the heparin polysaccharide. The function of heparin still remains under investigation because the sulfated saccharides have a three-dimensional structure for several reasons such as it changes upon binding to proteins and cell surfaces. ${ }^{2}$

\section{Heparin's Multifaceted Structure}

In this issue, Beurskens et al from the cardiovascular institute in Maastricht published a review on the pleiotropic anticoagulant and nonanticoagulant effects of heparin. ${ }^{3}$ They describe in detail the structure of heparin as a glycosaminoglycan. The chemical structure of heparin is commonly known by its

received

August 11, 2020

accepted

August 11, 2020

Address for correspondence Ludovic Drouet, MD, PhD, CREATIF, Cardiology Department, Hôpital Lariboisiere, Paris, France (e-mail: Ludovic.drouet@aphp.fr).

anticoagulant activity toward factor Xa and thrombin, which is mostly related to its high affinity binding to antithrombin (AT). Low affinity binding of heparin to AT mediates anticoagulant as well as nonanticoagulant action. Furthermore, the structural composition of heparin varies between species and even tissues; commercially available forms of heparin are typically derived from porcine intestinal mucosa and rarely from bovine intestinal mucosa; from bovine lung it is not extracted any more for clinical use. The growing demand for heparins has pushed us to consider other sources, such as from the ovine intestinal mucosa, and bioengineered heparin.

Some additional structural aspects of heparin compared with Beurskens et $\mathrm{al}^{3}$ include a relationship between different disaccharide components and how these relationships can identify the origin of a heparin sample obtained by industrial extraction processes. ${ }^{4}$

- Different structures for as many as five pentasaccharide sequences for the AT binding (ATB) region of mucosal bovine and porcine heparins were identified. ${ }^{5}$

- Two molecules of trisulfated disaccharides of an 18-unit oligomer containing ATB at reducing end are required to maximize the effect of AT on the anionic charge density of thrombin. 6

- The conformational flexibility of the iduronic acid chain components induces heparin's pleiotropic properties.

- Shorter chains than 18 monomers containing AT sites are devoid of anticoagulant activity but have antithrombotic activity.

It is astonishing that heparin's structure continues to surprise us today despite its use as a cornerstone therapy

(c) 2020 Georg Thieme Verlag KG Stuttgart · New York
DOI https://doi.org/ 10.1055/s-0040-1716543. ISSN 0340-6245. 
for thromboembolism for more than 50 years. This structural variation may be explained by heparin's glycosylic structure; a synthetic full-length active polyanionic oligosaccharide sequence is not yet commercially available, unlike proteins consisting of amino acids. Furthermore, improving physicochemical methods can now better detect three-dimensional peculiarities after binding to proteins. ${ }^{4}$

\section{Heparin's Anticoagulant and Nonanticoagulant Actions}

Beurskens et $\mathrm{al}^{3}$ have precisely described the many antithrombotic and anticoagulant actions of heparin. Antithrombotic actions include release of tissue factor pathway inhibitor, modulation of fibrinolytic activity, binding of chemokines and cytokines, and activation of growth factors. Nonanticoagulant actions include inhibition of tumor growth, metastasis, inflammation, and neutrophil extracellular traps (-Fig. 1). The authors conclude that the clinical benefits of heparin outweigh its many and potentially life-threatening side effects.

The multiple actions of heparin comprise the following processes:

- Heparin and other polyanions such as dermatan sulfate (located in the vessel wall) potentiate the antithrombotic activity of heparin cofactor II.

- Heparin inhibits protein Z (PZ) by potentiating a PZ inhibitor and thereby inhibiting blood coagulation.

- Heparin potentiates C1-esterase inhibitor action on the contact system by inhibiting kallikrein and factor XIIa. ${ }^{2}$

- Heparin inhibits the naturally occurring inhibitor of heparanase. $^{7}$

\section{Anticoagulant Actions of Heparin in COVID-19}

Beurskens et al reviewed heparin's actions before the coronavirus disease (COVID-19) pandemic caused by the severe acute respiratory syndrome coronavirus-2 (SARS-CoV-2). ${ }^{8}$ The most severely ill patients initially present with respiratory insufficiency that progresses to multiple organ dysfunction, involving septic-induced coagulopathy and eventually disseminated intravascular coagulation. ${ }^{9}$ The treatments of choice for disseminated intravascular coagulation are unfractionated heparin, low molecular weight heparin (LMWH), and fondaparinux. ${ }^{10}$ These reduce mortality and normalize coagulation marker levels, prothrombin time, activated partial thromboplastin time, fibrinogen levels, platelet count, and D-dimer levels. ${ }^{11}$ Twice daily administration of LMWH appears to have a more protective effect in COVID-19 patients than once daily dose, probably because of better nychthemeral coverage. ${ }^{12}$

\section{Heparin's Nonanticoagulant Antiviral Actions}

Unfractionated nonanticoagulant heparins are obtained by desulfation processes that modify the anionic charge of the AT domain, or by glycol split of heparin. Glycol split does not change the number and distribution of anionic charges and introduces flexible joints to the polymer chain, which increases the freedom of charge orientation toward the target proteins' cationic sites. Another therapeutic application of heparin is its use as an inhibitor of viral adhesion. ${ }^{13}$ This is also supported by the observation that heparin disrupts the interaction of the SARS-CoV-2 surface protein Spike with its host cell receptors of various organs via its S1 receptor ${ }^{14}$ as follows:

- Angiotensin-converting enzyme 2, a metallopeptidase, was identified as one of the functional binding receptors allowing SARS-CoV to enter host cells. ${ }^{15}$

- The immune changes associated with coagulation in COVID-19 patients may resemble the NETosis process observed during bacterial, fungal, and some viral infections. $^{16}$

- Lesions of the endothelium destroy the glycocalyx leading to microthrombotic reactions and extravascular fluid leaks. Heparin can enter the glycocalyx ${ }^{17}$ to mobilize syndecan pools ${ }^{18}$ and partly take over syndecan 1 function. ${ }^{19}$ This restores glycocalyx function in the vascular endothelium to prevent inflammation ${ }^{20}$ and reduce septic shock. $^{18}$

\section{Heparin and \\ Heparin-like compounds}

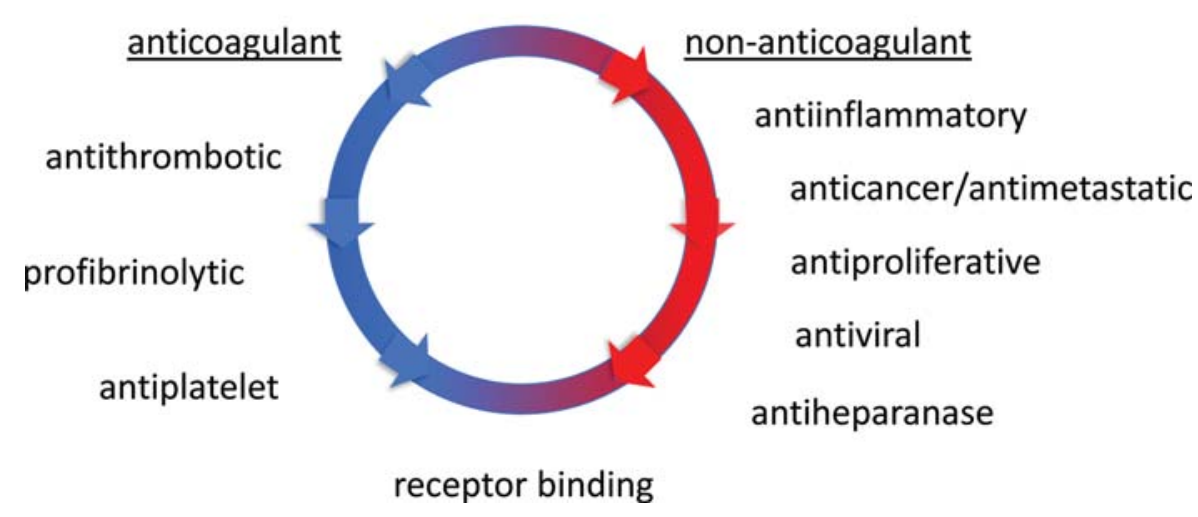

Fig. 1 Interplay of anticoagulant and nonanticoagulant actions of heparin and heparin-like compounds on biological functions. 


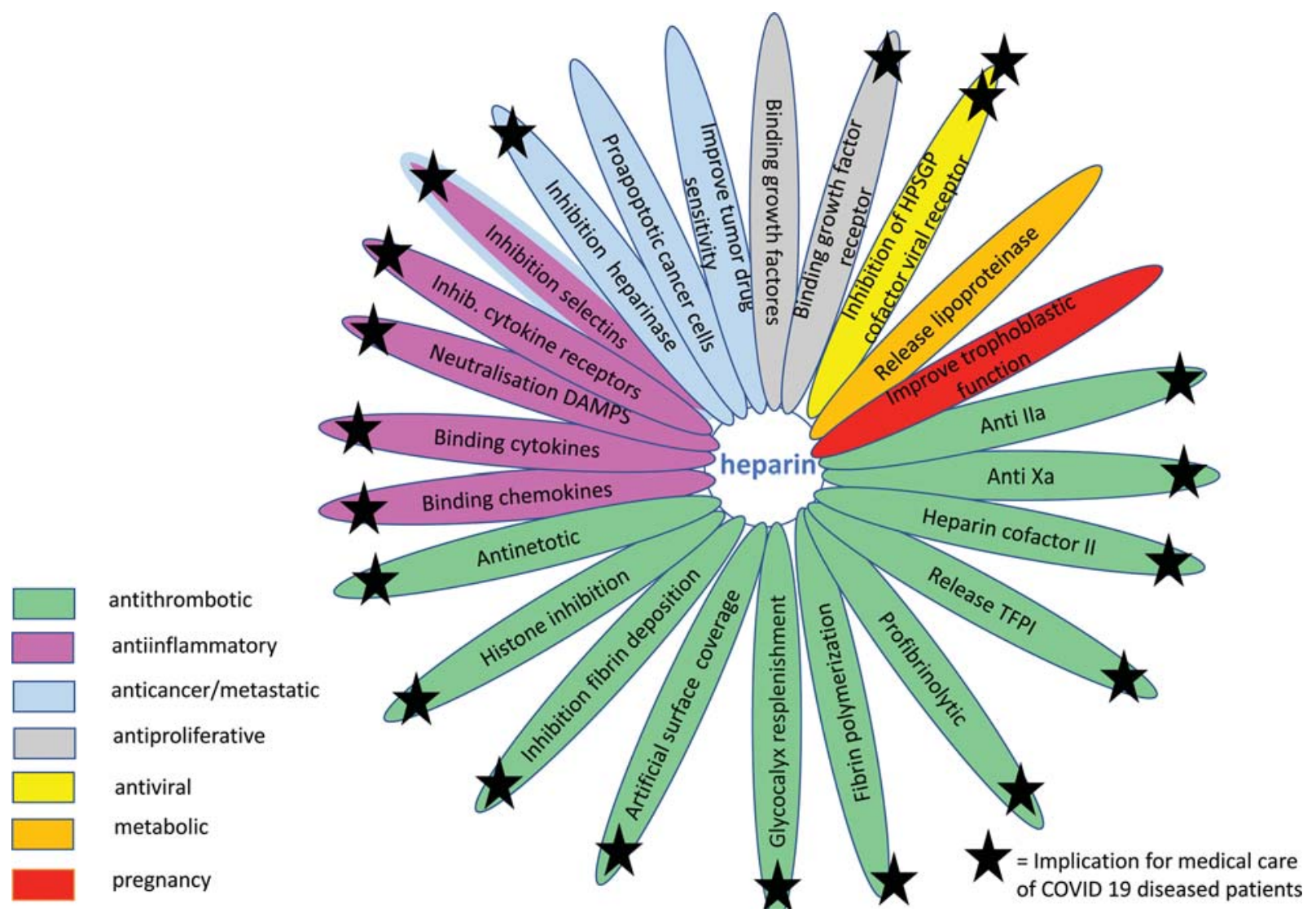

Fig. 2 Actions of heparin classified as beneficial that could have implication for medical care of COVID-19 patients.

- Autopsies of patients who died of COVID-19 revealed microvascular thrombosis in many organs such as lung, liver, and heart, ${ }^{21,22}$ as well as neurological effects such as severe acute hearing loss which indicate viral sepsis. ${ }^{23}$

Heparins achieve their multiple nonanticoagulant actions by inhibiting heparanase, which is elevated in malignancies, chronic inflammation, atherosclerosis, and Alzheimer's disease $^{7}$ (-Fig. 2). Advances in the field are presented at annual symposia ${ }^{24,25}$; the 28 th symposium will be postponed until 2021 because of the COVID-19 pandemic. The anticoagulant and nonanticoagulant actions of heparin make it a promising candidate for the treatment of COVID-19.

\section{Extended Anticoagulation and COVID-19}

Ideally, heparins should be administered to COVID-19 patients as early as possible. Before hospital admittance, anticoagulation therapy should be in the form of indirect-acting vitamin- $\mathrm{K}$ antagonists (VKA) or direct-acting oral anticoagulants (DOACs) in patients with nonvalvular atrial fibrillation and thromboembolism. ${ }^{26}$ Upon hospitalization, anticoagulation therapy should be switched as soon as possible to heparin/LMWH to ensure beneficial effects and to reduce interactions of VKA and DOACs during polypharmaceutical treatment of COVID-19. The presence of VKA and DOACs needs to be determined by rapid and accurate point of care methods.
- VKA can be detected by measuring the international normalized ratio in plasma samples. ${ }^{27}$

- DOACs can be detected using the DOAC Dipstick in urine samples. ${ }^{28}$

Before recovered patients are discharged from hospital, therapy should be switched from heparin/LMWH to VKA or DOACs after the anticoagulant effects of treatment have been specifically tested. ${ }^{29}$

\section{What the Future May Offer}

Our understanding of the chemical structure of heparin and its derivatives and their mode of action is increasing. In parallel, our knowledge of heparin's biological functions in plasma and on cell surfaces and receptors is also increasing. This in turn increases the spectrum of medical therapies and therapeutic indications that heparin can offer. Specific efforts are being undertaken to modify heparin to improve its safety and decrease the risk of bleeding complications. Promising approaches for treatment of COVID-19 and other nonthrombotic diseases may focus on heparin's nonanticoagulant effects and the inhibition of heparin by heparanases.

Conflict of Interest

None declared. 


\section{References}

1 Lindahl U, Li J-P. Heparanase - discovery and targets. Adv Exp Med Biol 2020;1221:61-69

2 Mulloy B, Hogwood J, Gray E, Lever R, Page CP. Pharmacology of heparin and related drugs. Pharmacol Rev 2016;68(01):76-141

3 Beurskens DMH, Huckriede JP, Schrijver R, et al. The anticoagulant and nonanticoagulant properties of heparin. Thromb Haemost 2020;120(10):1371-1383

4 Rudd TR, Skidmore MA, Guimond SE, et al. Glycosaminoglycan origin and structure revealed by multivariate analysis of NMR and CD spectra. Glycobiology 2009;19(01):52-67

5 Naggi A, Gardini C, Pedrinola G, et al. Structural peculiarity and antithrombin binding region profile of mucosal bovine and porcine heparins. J Pharm Biomed Anal 2016;118:52-63

6 Mourier PAJ, Guichard OY, Herman F, et al. New insights in thrombin inhibition structure-activity relationships by characterization of octadecasaccharides from low molecular weight heparin. Molecules 2017;22(03):428

7 Cassinelli G, Torri G, Naggi A. Non-anticoagulant heparins as heparanase inhibitors. Adv Exp Med Biol 2020;1221:493-522

8 Huang C, Wang Y, Li X, et al. Clinical features of patients infected with 2019 novel coronavirus in Wuhan, China. Lancet 2020;395 (10223):497-506

9 Guan W-J, Ni Z-Y, Hu Y, et al; China Medical Treatment Expert Group for Covid-19. Clinical characteristics of coronavirus disease 2019 in China. N Engl J Med 2020;382(18):1708-1720

10 Bikdeli B, Madhavan MV, Gupta A, et al; Global COVID-19 Thrombosis Collaborative Group. Pharmacological agents targeting thromboinflammation in COVID-19: review and implications for future research. Thromb Haemost 2020;120(07): 1004-1024

11 Violi F, Pastori D, Cangemi R, et al. Hypercoagulation and antithrombotic treatment in coronavirus 2019: a new challenge. Thromb Haemost 2020;120(06):949-956

12 Paolisso P, Bergamaschi L, D’Angelo EC, et al. Preliminary experience with low molecular weight heparin strategy in COVID-19 patients. JACC Cardiovasc Imaging 2020. Doi: 10.1016/j.jcmg.2020.03.021

13 Clausen TM, Sandoval DR, Spliid CB, et al. SARS-CoV-2 infection depends on cellular heparan sulfate and ACE2. bioRxiv 2020. Doi: 10.1101/2020.07.14.201616

14 Mycroft-West CJ, Su D, Elli S, et al. The 2019 coronavirus (SARSCoV-2) surface protein (Spike) S1 receptor binding domain undergoes conformational change upon heparin binding. bioRxiv 2020. Doi: 10.1101/2020.02.29.971093

15 Du L, He Y, Zhou Y, et al. The spike protein of SARS-CoV-a target for vaccine and therapeutic development. Nat Rev Microbiol 2009;7(03):226-236

16 de Bont CM, Boelens WC, Pruijn GJM. NETosis, complement, and coagulation: a triangular relationship. Cell Mol Immunol 2019;16 (01):19-27
17 Bal Dit Sollier C, Berge N, Drouet L. Enoxaparin chains stored during chronic treatment are mobilized by a bolus of unfractionated heparin: insights from the STACKENOX study. Blood Coagul Fibrinolysis 2016;27(07):779-785

18 Nelson A, Berkestedt I, Schmidtchen A, et al. Increased levels of glycosaminoglycans during septic shock: relation to mortality and the antibacterial actions of plasma. Shock 2008;30(06): 623-627

19 Floer M, Götte M, Wild MK, et al. Enoxaparin improves the course of dextran sodium sulfate-induced colitis in syndecan-1-deficient mice. Am J Pathol 2010;176(01):146-157

20 Lipowsky HH, Lescanic A. Inhibition of inflammation induced shedding of the endothelial glycocalyx with low molecular weight heparin. Microvasc Res 2017;112:72-78

21 Varga Z, Flammer AJ, Steiger P, et al. Endothelial cell infection and endotheliitis in COVID-19. Lancet 2020;395(10234):1417-1418

22 Lax SF, Skok K, Zechner P, et al. Pulmonary arterial thrombosis in COVID-19 with fatal outcome: results from a prospective, singlecenter, clinicopathologic case series. Ann Intern Med 2020: M20-M2566. Doi: 10.7326/M20-2566

23 Harenberg J, Jonas JB, Trecca EMC. A liaison between sudden sensorineural hearing loss and SARS-CoV-2 infection. Thromb Haemost 2020;120(9):1237-1239

24 Harenberg J, Casu B. Heparin and its derivatives - present and future. Thromb Haemost 2009;102(05):801-803

25 Harenberg J, Casu B, Krämer R, et al. Glycosaminoglycans: anticoagulant and nonanticoagulant actions: a short history of symposia held at villa vigoni. Semin Thromb Hemost 2014;40(08): 831-836

26 Lip GYH, Collet JP, de Caterina R, et al. Antithrombotic therapy in atrial fibrillation associated with valvular heart disease: executive summary of a joint consensus document from the European heart rhythm association (EHRA) and European Society of Cardiology Working Group on thrombosis, endorsed by the ESC Working Group on Valvular Heart Disease, Cardiac Arrhythmia Society of Southern Africa (CASSA), Heart Rhythm Society (HRS), Asia Pacific Heart Rhythm Society (APHRS), South African Heart (SA Heart) Association and Sociedad Latinoamericana de Estimulación Cardíaca y Electrofisiología (SOLEACE). Thromb Haemost 2017;117 (12):2215-2236

27 Refaai MA, Shah V, Fernando R. Performance of the micro INR point-of-care system: a multicenter clinical trial. Thromb Haemost 2020;120(04):687-691

28 Harenberg J, Beyer-Westendorf J, Crowther M, et al; Working Group Members. Accuracy of a rapid diagnostic test for the presence of direct oral factor Xa or thrombin inhibitors in urine - a multicenter trial. Thromb Haemost 2020;120(01):132-140

29 Testa S, Paoletti O, Giorgi-Pierfranceschi M, et al. Switch from oral anticoagulants to parenteral heparin in SARS-CoV-2 hospitalized patients. Intern Emerg Med 2020;15(05):751-753 